\section{Overcoming a Teaching Obstacle: Simplified, Inexpensive, and Rapid Slide Duplication}

\author{
J.L. Nus ${ }^{1}$ \\ Department of Horticulture, Kansas State University, Manhattan, \\ KS 66506
}

Additional index words. education, visual aids, resident instruction

Visual aids play a critical role in conveying information in a classroom (Fleming, 1981; Sless, 1981). Slides offer a level of convenience that some other methods do not possess (Heinich et al., 1989). Developing thorough slide sets for individual lessons is extremely time-consuming if a course involves cultural or management techniques specific to certain regions of the country (Beard, 1973). Professional slide sets are available from the American Society for Horticultural Science and other professional societies but offer little flexibility in the lesson plan and are usually quite expensive. Duplicating appropriate slides from colleagues in other geographic locations is a realistic option, but only if slide duplication costs are minimized. A simple device is presented for duplicating slides quickly and inexpensively.

A device was constructed to backlight and photograph an original slide using a 1:1 macrolens, 35-mm single-lens reflex camera, a copy stand, an opaque reflector, forced cool air, and a photoflood light source (Fig. 1). Several duplicate slides were produced this way, using Ektachrome 100 film from randomly chosen originals. Ten pairs of slides were picked at random, and the unidentified original and duplicate were shown simultaneously to 33 horticulture students using identical projectors and screens. Students were asked to identify the duplicate slide, rate both slides $(1=$ extremely poor, $9=$ highest quality), and respond to the acceptability of both slides for classroom instruction. Paired $t$ tests were used to analyze the student response $;+1=$ correct identification or acceptability; $-1=$ an incorrect identification or unacceptability.

Received for publication 4 Sept. 1990. Contribution no. 91-99-J of the Kansas State Agr. Expt. Sta. Special thanks to Roth Gaussoin and Fred Anderson for assistance in the student survey and statistical analyses and graphic preparation, respectively. The cost of publishing this paper was defrayed in part by the payment of page charges. Under postal regulations, this paper therefore must be hereby marked advertisement solely to indicate this fact.

'Assistant Professor of Horticulture. professional photographic services is nearly twice as much for duplicate slides as use of a 36-exposure roll and the device described (\$0.78 vs. $\$ 0.43$ per slide for film and development). Mail-order prices for film and developing are approximately $\$ 0.30$ per slide (recent advertisements, Popular Photography). Also, local professional services may not be able to guarantee delivery in $<1$ week. Using the device, Ektachrome film allows for $1 \mathrm{~h}$ E-6 processing.

Horticultural education requires both specificity and breadth (LaSota and Soares, 1986), curricula must be current and relevant (Hegwood and Merritt, 1987), and resident instruction must be taken beyond the boundaries of the campus (Verkade et al., 1988). Economical development of "on-target" slide sets may help to accomplish these goals

\section{Literature Cited} slightly overexposed, the duplicates brought out better contrast; when it was underexposed, however, duplication using Ektachrome 100 film resulted in slides that were slightly too dark. Quality ratings and suitability judgment given to each slide of each slide pair tended to confirm this observation. Quality ratings averaged 8.2 for originals and 7.6 for duplicates. Students indicated that originals were acceptable for classroom instruction $97 \%$ of the time, whereas duplicates were acceptable $87 \%$ of the time (NS by paired $t$ tests). Slide film specifically for duplicating is available and may eliminate this problem (Eastman Kodak, personal communication). The use of certain filters and light source (e.g., Tungsten $3200 \mathrm{~K}$ for Ektachrome 100 film) might also have improved the results.

Duplicating slides using this device is very rapid and economical. The cost of local

Beard, J.B. 1973. Turfgrass: Science and culture Prentice-Hall, Englewood Cliffs, N.J.

Fleming, M. 1981. Characteristics of effective instructional presentation: What we know and what we need to know. Educ. Tech. July:33-38.

Hegwood, D.A. and R.H. Merritt. 1987. Horticultural curricula can benefit from national initiatives. HortScience 22(3):351-352.

Heinich, R., M. Molenda, and J.D. Russell. 1989. Instruction media and the new technologies of instruction. Macmillan, New York. to a degree: The proliferation of curriculum options in undergraduate horticulture. HortScience 21(3):538-539.

Sless, D. 1981. Learning and visual communication. John Wiley, New York.

Verkade, S.D., H.E. Drummond, and G.L. Zachariah. 1988. Resident instruction in agriculture for place-bound students. HortScience 23(6):955956.
LaSota, L.R. and S.D. Soares. 1986. Education

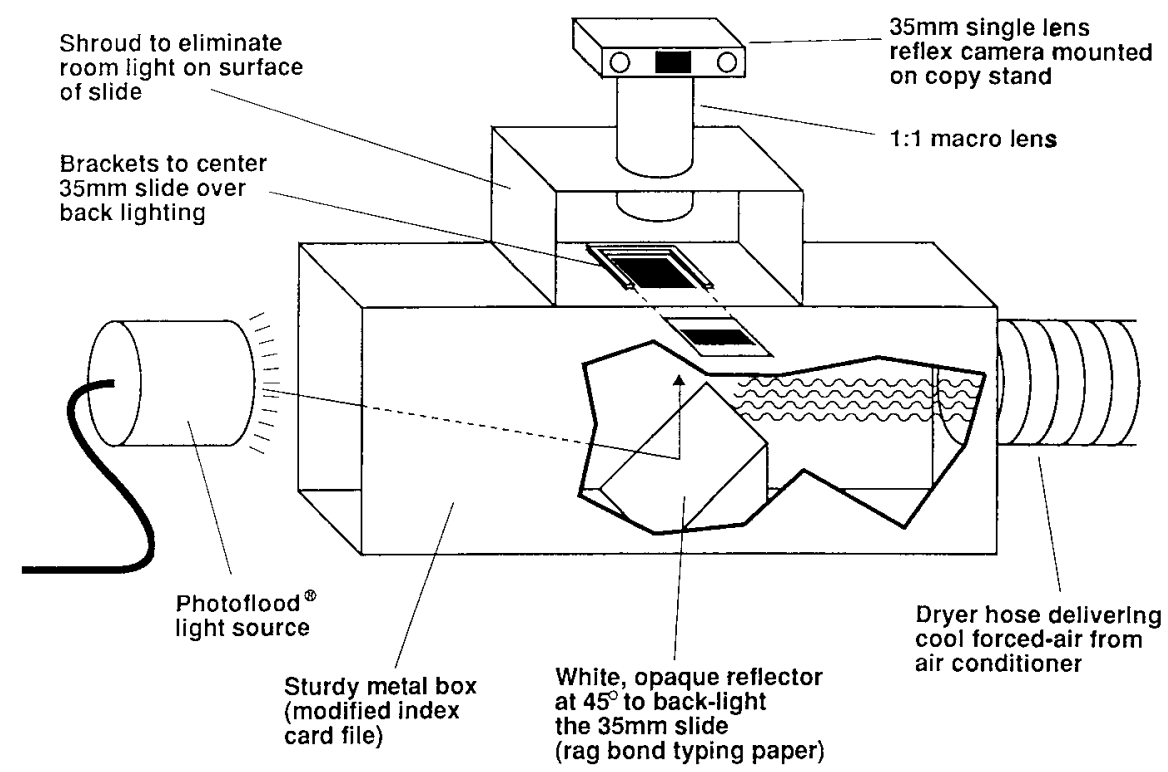

Fig. 1. Diagram of device used to produce duplicate slides by photographing original slides. 